\title{
Nocturnal Sleep Organization in Infants "at Risk" for Sudden Infant Death Syndrome
}

\author{
Y. NAVELET, C. PAYAN, A. GUILHAUME, AND O. BENOIT ${ }^{(43)}$ \\ Service d'Explorations Fonctionnelles et Unité de Réanimation Néonatale, Hopital A. Béclère, 92141 \\ Clamart, France/Y.N.J and U3 INSERM, CHU Pitié Salpêtrière, 75634 Paris Cedex 13 [C.P., A.G., O.B.]
}

\begin{abstract}
Summary
Nocturnal sleep organization was compared in normal infants and those "at risk" for sudden infant death syndrome (SIDS) (siblings and near-miss infants). Before 12 weeks of age, sleep modifications were observed in "at risk" infants. During their sleep they had a smaller percentage of intervening wakefulness with a higher amount of active sleep. Quiet and active sleep episodes had longer durations resulting in a longer sleep cycle. After 12 weeks, sleep organization tended to normalize. This fact is discussed as a possible factor for a SIDS event: a higher arousal threshold could play a critical role if homeostasy is disturbed during sleep, mainly at an age when the homeostatic control is not fully established.
\end{abstract}

\section{Abbreviations}

SIDS, sudden infant death syndrome

W, wakefulness

AS, active sleep

QS, quiet sleep

TS, transitional sleep

C, control

$\mathrm{S}$, siblings

NM, near-miss

Polygraphic recordings in infants "at risk" for SIDS have been extensively carried out since the first Steinschneider paper (37). This author hypothesized a relationship between SIDS and apnea occurring during sleep. Therefore, most studies since then have been devoted to physiological functions during sleep such as respiratory, cardiovascular, and autonomic systems, gastrooesophageal reflux, etc. as reviewed by Hoppenbrouwers and Hodgman (19) and Kelly and Shannon (24).

Sleep organization with relation to SIDS has only been taken into account in the past few years $(4,12,15,31)$. The period between 6 and 12 weeks of age appears to be critical in the development of many physiological functions: circadian rhythm (25), body temperature [Jundell as cited by Minors and Waterhouse (29)], heart rate $(14,16)$, respiratory rhythm $(7,20)$, electrodermogram (6), as well as sleep organization (30).

The aim of the present study is to compare the sleep organization of normal and "at risk" infants of about the same age corresponding to the maximum frequency of SIDS events.

\section{MATERIALS AND METHODS}

Nocturnal sleep organization was studied in 77 infants ages between 4 weeks and 12 months ( 35 boys, 42 girls). The population was distributed as follows (Table 1). There were 19 control infants ( 8 boys, 11 girls) having no pathological antecedents either personally or within the immediate family. Fifty-eight infants were "at risk" for SIDS divided into 24 siblings ( 9 boys, 15 girls) of an infant who died as a result of SIDS but who themselves had no personal pathology and 34 near-miss infants (18 boys, 16 girls) having suffered one or more episodes of unexplained apnea with pallor or cyanosis necessitating vigorous stimulations or mouth to mouth resuscitation for survival.

All these children were full-term babies with Apgar scores and birth weight in the normal range. Most of them had been hospitalized for at least 2 days prior to the recording session whereas only a few came directly from home in which case the mother was present in the laboratory during the entire recording night and was responsible for feedings.

The 77 nocturnal polygraphic records analyzed in this study correspond to the 77 children. Some of the children were recorded several times, but for the present study only the first recording was taken into account. The records had a mean duration of $474 \mathrm{~min}(\mathrm{SD}=14.5)$ and were performed in the sleep laboratory between 20.30 and 07.30 . The classical polygraphic method was used: electrodes were pasted to the scalp for the electroencephalogram, to the chin for the electromyogram, and to the thorax for the electrocardiogram. An accelerometer was fixed to one eyelid for the electro-oculogram. Respiration was recorded at three levels: nasal with nasal thermistors, thoracic, and abdominal with graphite rubber belts. Six electroencephalogram derivations adapted from the International 10-20 electrode system were used: FP2-C4, C4-O2, O2-T4 and FP1C3, C3-O1, O1-T3.

The recordings were visually scored by 20 -sec epochs. Based on our previous study of sleep organization in normal babies (30), the population was divided into two age groups, under and over 12 weeks of age, a time which represents an important step in sleep maturation. Because of the limited number of infants, a more detailed analysis of the influence of age was not performed. In order to compare the intrasleep organization, whatever the age, only four stages were identified: intervening wakefulness, active sleep, quiet sleep, and transitional sleep, according to the criteria established by Anders et al. (1), Souquet et al. (36), and Dreyfus-Brisac et al. (8). The scoring criteria have been described in a previous publication (30).

After visual scoring of the records, the different data involving sleep and spontaneous awakenings were computer analyzed. Absolute and relative amounts of sleep states during the entire night, hour by hour and cycle by cycle, were computed and the hypnograms were printed by computer program. AS cycle length was measured from the beginning of one AS episode to the beginning of the next. AS episodes separated by less than $15 \mathrm{~min}$ were grouped together, and the mean length of AS and QS episodes were calculated from all continuous episodes equal to or more than, respectively, $3 \mathrm{~min}$ for AS and $5 \mathrm{~min}$ for QS. The respective numbers and mean duration of awakenings were 
analyzed for durations of $>20 \mathrm{sec},>1 \mathrm{~min}$, and $>5 \mathrm{~min}$. The statistical study was done by means of one-way analysis of variance. A preliminary brief report has already been published for some of these results (32).

\section{RESULTS}

Table 2 gives for the three groups the mean durations of night recordings and percentages of $\mathrm{W}, \mathrm{QS}, \mathrm{AS}$, and TS. This clearly shows that night sleep composition varied among groups before 12 weeks of age but did not differ after this age. Significant differences were observed for W and AS. The near-miss group had the lowest amounts of W and the highest of AS; the siblings were between the controls and the near-miss infants for both stages. The amount of QS was increased in siblings and nearmisses compared to controls but in a nonsignificant way.

Internal sleep organization. Table 2 gives the significant differences obtained for sleep parameters among groups before and after 12 weeks of age. Differences in total amounts for infants before 12 weeks are related to 1 ) a decrease in the mean duration of the awakenings longer or equal to $5 \mathrm{~min}$. The number of these awakenings $>5 \mathrm{~min}$ expressed for $100 \mathrm{~min}$ of sleep was similar for all three groups $(\mathrm{C}=3.8, \mathrm{~S}=5.2, \mathrm{NM}=3.2)$. 2) The mean duration and the rhythm of occurrence of AS episodes were

Table 1. Distribution and mean age in weeks $( \pm S D)$ of the studied population: within each group, the mean age of $C, S$, and NM did not differ significantly.

\begin{tabular}{ccc} 
& \multicolumn{3}{c}{ and $N M$ did not differ significantly. } \\
\hline $\mathrm{C}$ & $<12$ weeks & $>12$ weeks \\
\hline $\mathrm{S}$ & 6 & 13 \\
& $(5.7 \mathrm{wk} \pm 2)$ & $(18.8 \mathrm{wk} \pm 8.2)$ \\
$\mathrm{NM}$ & 15 & 9 \\
& $(7.2 \mathrm{wk} \pm 2.3)$ & $(18.8 w \mathrm{k} \pm 9.8)$ \\
& 17 & 17 \\
\hline
\end{tabular}

increased in the NM group when compared to the other groups. 3) Although the total amount of QS was not significantly different among groups, the mean duration of QS episodes was longer in NM infants. Thus, the NM group seemed to have more stable episodes both of QS and AS and shorter durations of awakenings.

After 12 weeks of age, some differences in intrasleep organization were still observed; the AS rhythm of NM remained longer than in the other groups, while the mean duration of QS episodes tended to approach those of the other groups.

Sleep organization within groups before and after 12 weeks of age. The significant differences between and after 12 weeks of age within groups are indicated in Table 3. In control infants over 12 weeks, total amounts of $\mathrm{W}$ were significantly lower than for those under 12 weeks. In the other two groups, similar amounts of $\mathrm{W}$ were observed at both ages. The increase of QS with age was observed in the three groups and was more pronounced in the $\mathrm{C}$ infants. The percentage of AS did not change with age in the $C$ and $S$ groups while it decreased significantly in the NM group (Table 4).

Figure 1 gives the mean number of all awakenings per 100 min of the different sleep stages for the two age groups $( \pm \mathrm{SE})$ and separately for C, S, and NM. Awakenings were significantly less frequent during QS than during AS or TS in both age groups $(F=29.4$ and 23.5, $P<0.001$, df 2:112 and 2:116). Their number decreased significantly with age in AS and TS but remained stable during QS. A significant difference in the mean number of awakenings among $\mathrm{C}, \mathrm{S}$, and NM was found only for AS after 12 weeks of age $(F=3.2, P<0.05, d f 2: 37)$ : NM had fewer awakenings than $\mathrm{C}$ and $\mathrm{S}$. When the effect of age was analyzed separately in $\mathrm{C}, \mathrm{S}$, and NM a significant decrease in the number of awakenings between the two age groups was found only for AS in S and NM but not in C (S: $F=4.7, P<0.04$, $d f$ 1:23; NM: $F=10.9, P<0.002, d f 1: 33$ ).

Thus, to summarize our results, infants at risk for SIDS exhibited less intervening wakefulness and more AS during their sleep before 12 weeks of age. Beyond this age, sleep organization tended to normalize.

Table 2. Total sleep recording (TSR) time and percentage of wakefulness, quiet sleep, active sleep, and transitional sleep in the three groups as a function of age

\begin{tabular}{|c|c|c|c|c|c|c|c|c|c|c|}
\hline \multirow{5}{*}{$\begin{array}{l}\mathrm{C} \\
19 \\
\mathrm{~S} \\
24 \\
\mathrm{NM} \\
34\end{array}$} & \multicolumn{5}{|c|}{$<12$ weeks } & \multicolumn{5}{|c|}{$>12$ weeks } \\
\hline & $\begin{array}{c}\text { TSR } \\
(\mathrm{min})\end{array}$ & W & \multicolumn{2}{|c|}{$(\%)$} & TS & $\begin{array}{c}\text { TSR } \\
(\mathrm{min}) \\
\end{array}$ & \multicolumn{4}{|c|}{$(\%)$} \\
\hline & $475 \pm 12$ & $36 \pm 15$ & $24 \pm 7.5$ & $21.5 \pm 8.5$ & $18.5 \pm 6.5$ & $462 \pm 44$ & $19 \pm 9$ & $41.6 \pm 10$ & $20 \pm 5.5$ & $19.5 \pm 9$ \\
\hline & $493 \pm 83$ & $27 \pm 10$ & $31 \pm 6$ & $23 \pm 7.5$ & $19 \pm 8$ & $458 \pm 35$ & $21.5 \pm 10$ & $38.5 \pm 8$ & $23 \pm 7.5$ & $17 \pm 8$ \\
\hline & $466 \pm 71$ & $\begin{array}{l}21 \pm 8.5 \\
F=4.74 \\
P<0.025\end{array}$ & $30.5 \pm 10$ & $\begin{array}{c}34.5 \pm 11 \\
F=6.2 \\
P<0.01\end{array}$ & $14 \pm 7$ & $489 \pm 73$ & $21.5 \pm 12.5$ & $38.5 \pm 8.5$ & $23.5 \pm 7$ & $16 \pm 6$ \\
\hline
\end{tabular}

Table 3. Composition of internal sleep parameters among the three groups under and over 12 weeks of age

\begin{tabular}{|c|c|c|c|c|c|c|c|c|}
\hline & \multicolumn{4}{|c|}{$<12$ weeks } & \multicolumn{4}{|c|}{$>12$ weeks } \\
\hline & $\mathrm{C}$ & $\mathrm{S}$ & NM & Test & $\mathrm{C}$ & $\mathrm{S}$ & NM & Test* \\
\hline $\begin{array}{l}\text { Mean awakening } \\
\text { length }(>5 \mathrm{~min})\end{array}$ & $35.3 \pm 27.5$ & $13 \pm 5.7$ & $14.7 \pm 10.8$ & $\begin{array}{c}F=6.7 \\
P<0.0035\end{array}$ & $17.4 \pm 10.7$ & $19.1 \pm 8.7$ & $25.7 \pm 23.1$ & $\begin{array}{c}F=1 \\
\text { NS }\end{array}$ \\
\hline $\begin{array}{l}\text { Mean AS episode } \\
\text { length }(>3 \mathrm{~min})\end{array}$ & $25.2 \pm 11.4$ & $21.8 \pm 11.4$ & $30 \pm 8.7$ & $\begin{array}{c}F=3.9 \\
P<0.05\end{array}$ & $15.5 \pm 4.3$ & $17.9 \pm 5.3$ & $19.7 \pm 5.6$ & $\begin{array}{c}F=2.4 \\
\quad \mathrm{NS}\end{array}$ \\
\hline AS cycle length & $53 \pm 7$ & $53.7 \pm 11.6$ & $63 \pm 11.4$ & $\begin{array}{c}F=3.5 \\
P<0.05\end{array}$ & $51.2 \pm 5.3$ & $54 \pm 4.7$ & $61.7 \pm 12.6$ & $\begin{array}{l}F=5.2 \\
P<0.01\end{array}$ \\
\hline $\begin{array}{l}\text { Mean QS episode } \\
\text { length }(>5 \mathrm{~min})\end{array}$ & $17.1 \pm 4$ & $18.8 \pm 3$ & $24.3 \pm 9$ & $\begin{array}{r}F=4.7 \\
P<0.03\end{array}$ & $23.5 \pm 7.2$ & $21.8 \pm 4.4$ & $26.6 \pm 4.4$ & $\begin{array}{c}F=2.7 \\
N S \\
(P<0.08)\end{array}$ \\
\hline
\end{tabular}

* NS, not significant. 
Table 4. Significant differences under and over 12 weeks of age for each group*

\begin{tabular}{|c|c|c|c|}
\hline & $\begin{array}{c}C \\
<12 />12 w k\end{array}$ & $\begin{array}{c}S \\
<12 />12 w k\end{array}$ & $\begin{array}{c}\mathrm{NM} \\
<12 />12 \text { wk } \\
\end{array}$ \\
\hline W & $\begin{array}{c}t=3.1 \\
P<0.01\end{array}$ & NS & NS \\
\hline QS & $\begin{array}{c}t=3.8 \\
P<0.01\end{array}$ & $\begin{array}{c}t=2.9 \\
P<0.02\end{array}$ & $\begin{array}{c}t=2.5 \\
P<0.02\end{array}$ \\
\hline AS & NS & NS & $\begin{array}{c}t=3.4 \\
P<0.01\end{array}$ \\
\hline TS & NS & NS & NS \\
\hline
\end{tabular}

* NS, not significant.

\section{DISCUSSION}

Previous results in normal infants $(30)$ have evidenced a noticeable change in sleep organization between 6 and 12 weeks of age marked by an increase of QS and a decrease of $\mathrm{W}$, changes which appeared near the age of both spindle maturation and circadian rhythm occurrence $(18,28)$. These results are in agreement with other studies showing that 3 months of age is a critical step in the wake-sleep cycle $(5,11,17)$. After that age, AS is mainly distributed during the night and $\mathrm{W}$ during the day (9), suggesting that the main characteristics of the nycthemeral rhythm are established around 3 months. For all these reasons, we divided our population according to age: under and over 12 weeks. The aim of the present study was not to analyze precisely the effect of age on sleep-wake organization; considerably larger groups would have been required.

In the present study as well as in a few others, at risk infants, usually under 12 weeks of age, have exhibited differences in their sleep organization when compared to normal infants of the same age. These differences mainly concerned the characteristics of intrasleep awakenings, active sleep, and sleep-wake temporal sequence. Our results in a transversal study indicating a lower number of spontaneous awakenings during sleep in at risk infants are in agreement with the general findings of a decrease of intrasleep wakefulness in other studies $(4,15)$. In a longitudinal study, Challamel et al. (3) found that NM infants woke up less often but for a longer period of time than normal infants between 2 and 3 months of age. Harper et al. (15) observed longer interawakening periods and an absence of short $\mathrm{W}$ epochs in at risk infants of the same age. The longer duration of AS and QS episodes resulting in a longer AS cycle in NM infants found in our study could be due to this absence of short awakenings.

As in our study, a significant increase of AS in NM infants was noticed by Harper et al. (15) and in many other studies (3, $12,13,34)$. Other sleep abnormalities have been found in NM infants, namely an excessive variability of sleep spindle frequency (26) before 6 months of age and disruption of sleep stage patterns from the first week of life to 6 months of age (13).

All these results indicate a relative inability of at risk infants to awake from sleep, whatever the stage, and to maintain these awakenings. These sleep disturbances seem more marked around 2 and 3 months of age, but they have been observed as early as the first week of life (13) and seem to continue to some degree until 6 months $(13,34)$. We also noticed a longer AS rhythm and a decrease in the number of awakenings in AS in NM infants after 3 months.

These data support a developmental disturbance of the sleepwake organization in at risk infants which tends to progressively normalize around 6 months of age or even later.

The relative inability of at risk infants to arouse from sleep could lead to a SIDS event. In a normal subject, an arousal response represents a major protective mechanism when a sudden disturbance of the level of any physiological variables (blood pressure, blood gases, heart rate, body temperature, etc.) occurs. If the homeostatic feedback controls are insufficient to reestablish normal values, the arousal response allows a rapid return to optimal capacity of homeostatic regulation. During sleep, the threshold for an arousal response is increased, particularly during AS. Such a mechanism has been especially studied for the respiration function by Phillipson (33) and Sullivan (39) and such hypothesis has been discussed by Hoppenbrouwers and Hodgman (19) and Guilleminault et al. (10). These last authors noticed in NM an increase of the number of apneas just before an awakening.

In has been shown that thresholds for regulation of some physiological parameters in rapid eye movement sleep (for instance, hypercarbia or hypoxia) are higher and less precise than in non-rapid eye movement sleep (33). Therefore, the increased amount of AS in at risk infants could be an additional factor of risk of a SIDS event. In babies, the mechanism controlling the homeostatic regulation is probably not yet fully matured. An incomplete maturation of the control mechanisms by the autonomic and central nervous system is suggested by the variability of the main physiological functions observed during the period of emergence of the circadian rhythm $(20,29)$. The stability of the circadian rhythm is not achieved before 6 to 8 months of age and sometimes later (38). All this suggests a higher probability of dysregulation in infants than in adults; thus, the integrity of the arousal response is crucial for survival in the first months of life, and if this response fails to occur, a SIDS event might result.

Recently Hunt et al. (21) as well as McCulloch et al. (27) gathered evidence of a higher arousal threshold both to hypercapnic and hypoxic tests in NM infants, a result which indicates a specific factor for SIDS risk. But Ariagno et al. (2) failed to find significant differences in ventilatory response to hypercarbia in NM and control infants. Moreover, Shannon et al. (35) found evidence of abnormal ventilatory regulation in NM for SIDS compared to normal controls of similar age. Weissbluth (41) also hypothesized a relationship between progesterone blood level, sleep apneas, and a higher arousal threshold leading to an in-

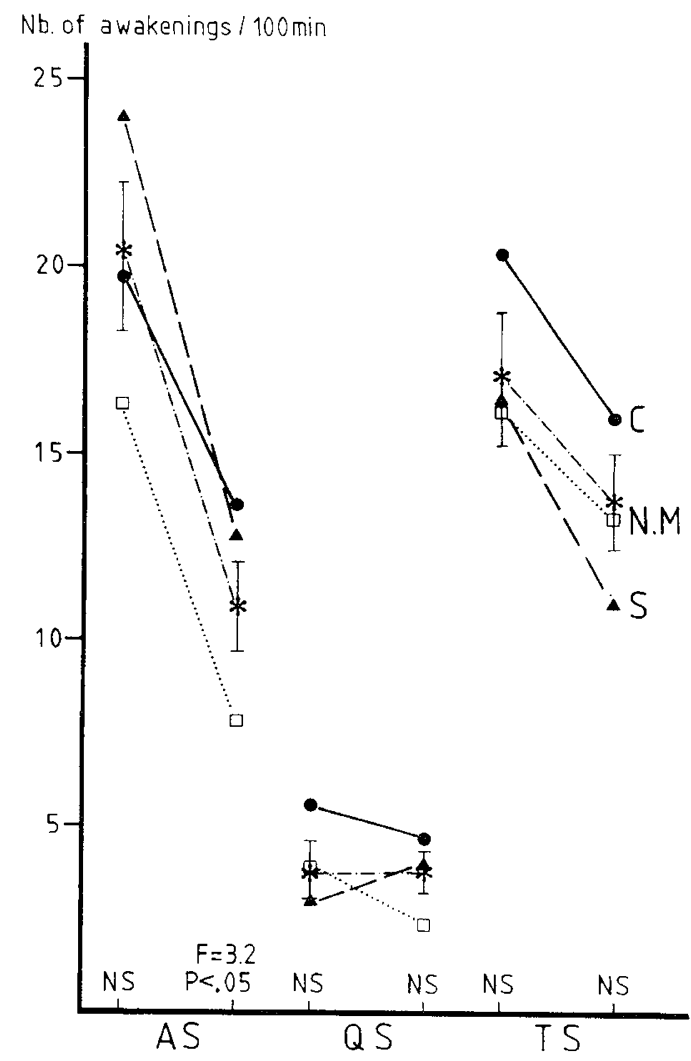

Fig. 1. Mean number of awakenings for $100 \mathrm{~min}$ of a given sleep stage for the whole population $(*, \pm S E)$ and separately for $C, S$, and NM. The lefihand curves represents the values before 12 weeks of age and the righthand curves are those found after 12 weeks. 
creased risk of a SIDS event in infants with a lethargic temperament. In addition, Kahn et al. (23) suggested a role of vagal hypersensitivity in the physiopathology of SIDS.

In addition, factors common to all babies, could occasionally depress the arousal response. Among these are: the appearance of the circadian rhythm between 2 and 3 months; the circadian trough of vigilance mechanisms at the end of the night; an occasional sleep deprivation; central nervous system depressants (22), etc.

Therefore, two different types of factors of risk can be described: 1) those which play a role in homeostatic control and/ or the probability of a disturbance of this homeostasy; and 2) those which depress the arousal response if a noxious event (such as gastro-esophageal reflux, hyperthermia, hypercapnia, etc.) occurs. Any of these factors could be present either permanently or occasionally, but when they occur simultaneously they could result in a SIDS event. Thus, those infants who do have one of these factors permanently should be considered to be at risk. Furthermore, a depressed arousal response may better explain the possible roles of many factors of risk for SIDS already described in epidemiological studies (40); none of these factors alone could be responsible for a SIDS event. For the present, it seems that a multifactorial process is the most reasonable explanation of SIDS events.

\section{REFERENCES AND NOTES}

1. Anders T, Emde R. Parmelee A (eds) 1971 A manual of standardized terminology techniques and criteria for scoring of states of sleep and wakefulness in newborn infants. Brain Information Service, University of California. Los Angeles. CA

2. Ariagno R. Nagel L, Guilleminault C 1980 Waking and ventilatory responses during sleep in infants near-miss for sudden infant death syndrome. Sleep $3: 351$

3. Challamel MJ, Debilly G, Leszczynski MC, Revol M, Jouvet M 1983 A longitudinal study of sleep organization of near-miss infants during the first six months of life. In: Koella WP (ed): Sleep 1982. Basel, Karger, pp 304 307

4. Challamel MJ, Revol M. Leszczynski MC, Debilly G 1981 Organisation nycthemerale des états de vigilance chez le nourrisson normal et le nourrisson dit "réchappé de mort subite" Rev EEG Neurophysiol 11:28

5. Crowell DH, Kapuniai LE, Boychuk RB, Light MJ, Hodgman JE 1982 Daytime sleep stage organization in three month old infants. Electroenceph Clin Neurophysiol 53:36

6. Curzi-Dascalova L, Dreyfus-Brisac C 1976 Distribution of skin potential responses according to states of sleep during the first months of life in human babies. Electroenceph Clin Neurophysiol 41:399

7. Curzi-Dascalova L, Lebrun F, Korn G 1983 Respiratory frequency according to sleep states and age in normal premature infants: a comparison with fullterm infants. Pediatr Res 17:152

8. Dreyfus-Brisac C 1979 Ontogenesis of the brain, bio-electrical activity and sleep organization in neonates and infants. In: Falkner F, Tanner JM (eds): Human Growth. New York, Plenum Press, pp 157-182

9. Fagioli I. Salzarulo P 1982 Sleep states development in the first year of life assessed through $24 \mathrm{~h}$ recordings. Early Human Dev 6:215

10. Guilleminault C, Ariagno R, Korobkin R, Coons S, Owen-Boeddiker M, Baldwin R 1981 Sleep parameters and respiratory variables in "near miss" sudden infant death syndrome infants. Pediatrics $68: 354$

11. Guilleminault $C$. Souquet $M 1979$ Sleep states and related pathology. In: Korobkin R, Guilleminault C (eds): Advances in Perinatal Neurology, Vol 1. New York, Spectrum Publications, pp 225-247

12. Haddad GG. Walsh EM, Leistner HL, Grodin WK, Mellins RB 1981 Abnormal maturation of sleep states in infants with aborted sudden death infant syndrome. Pediatr Res 15:1055

13. Harper RM. Frostig Z, Taube D. Hoppenbrouwers T, Hodgman JE 1983 Development of sleep-waking temporal sequencing in infants at risk for the sudden infant death syndrome. Exp Neurol 79:82

14. Harper RM. Leake B, Hodgman JE, Hoppenbrouwers T 1982 Developmental patterns of heart rate and heart rate variability during sleep and waking in normal infants and infants at risk for the sudden infant death syndrome. Sleep $5: 28$
15. Harper RM, Leake B, Hoffman H, Walter DO. Hoppenbrouwers T, Hodgman J. Sterman MB 1981 Periodicity of sleep states is altered in infants at risk for the sudden infant death syndrome. Science 213:1030

16. Harper RM, Leake B, Hoppenbrouwers T, Sterman MB, McGinty DJ, Hodgman J 1978 Polygraphic studies of normal infants and infants at risk for the sudden infant death syndrome: heart rate and variability as a function of state. Pediat Res 12:778

17. Harper RM, Leake B, Miyahara L, Lason J, Hoppenbrouwers T, Sterman MB Hodgman $J 1981$ Temporal sequencing in sleep and waking states during the first 6 months of life. Exp Neurol 72:294

18. Hellbrugge $\Upsilon 1974$ The development of circadian and ultradian rhythms of premature and full term infants. In: Scheving LE, Halberg F, Pauly J (eds): Chronobiology. Stuttgart, Thieme, pp 339-341

19. Hoppenbrouwers T, Hodgman JE 1982 Sudden infant death syndrome (SIDS): an intergration of ontogenetic, pathologic, physiologic and epidemiologic factors. Neuropediatrics 13(suppl):36

20. Hoppenbrouwers T, Jensen DK. Hodgman J, Harper RM. Sterman MB 1980 The emergence of a circadian pattern in respiratory rates: comparison between control infants and subsequent siblings of SIDS. Pediatr Res 14:345

21. Hunt CE. McCulloch K, Brouillette R 1981 Diminished hypoxic ventilatory responses in near-miss sudden infant death syndrome. J Appl Physiol $50: 1313$

22. Kahn A, Blum D 1982 Phenothiazines and sudden infant death syndrome. Pediatrics 70:75

23. Kahn A, Riazi J, Blum D 1983 Oculocardiac reflex in near miss for sudden infant death syndrome infants. Pediatrics 71:49

24. Kelly DS, Shannon DC 1982 Sudden infant death syndrome and near sudden infant death syndrome: a review of the literature 1964 to 1982 . Pediatr Clin N Am 9:1241

25. Kleitman N, Engelman TG 1953 Sleep characteristics of infants. J Appl Physiol 6:269

26. Lacey DJ 1983 Sleep EEG abnormalities in children with near miss sudden infant death syndrome, in siblings and in infants with recurrent apnea. Pediatr 102:855

27. McCulloch K, Brouillette RT, Guzzetta AJ, Hunt CE 1982 Arousal responses in near miss sudden infant death syndrome and in normal infants. J Pediat 101:911

28. Meier-Koll A Hall U, Hellwig U, Kott G, Meier-Koll V 1978 A biologica oscillator system and the development of sleep-waking behavior during early infancy. Chronobiologia 5:425

29. Minors DS, Waterhouse JM 1981 Rhythms in the infant and the aged. In Minors D, Waterhouse JM (eds): Circadian Rhythms and the Human. Bristol, J. Wright and Sons, pp 166-186

30. Navelet $Y$, Benoit O. Bouard G 1982 Nocturnal sleep organization during the first months of life. Electroenceph Clin Neurophysiol 54:71

31. Navelet $Y$, Benoit O, Lacombe J 1979 Respiration et sommeil de nuit chez des enfants "à risque" pour la mort subite du nourrisson. Rev EEG Neurophysiol 9:258

32. Navelet Y Payan C. Guilhaume A, Benoit O 1982 L'organisation du sommeil est elle perturbée chez l'enfant "à risque" pour la mort subite inexpliquée du nourisson. Arch Fr Pediatr 39:125

33. Phillipson EA 1978 Control of breathing during sleep. Am Rev Respir Dis 118:909

34. Rosen CL. Frost JD, Harrison GH 1983 Infant apnea: polygraphic studies and follow up monitoring. Pediatrics 77:731

35. Shannon DS, Kelly DH, O'Connell K 1977 Abnormal regulation of ventilation in infants at risk for sudden infant death syndrome. N Engl J Med 297:747

36. Souquet M, Peraita R, Guilleminault C, Dement WC 1976 Scoring system for infants during the first year of life. In: Chase WH, Mitler M, Walter PL (eds): Sleep Research, Vol 5. Los Angeles, BIS/BRI UCLA, p 209

37. Steinschneider A 1972 Prolonged apnea and the sudden infant death syndrome: clinical and laboratory observations. Pediatrics 50:646

38. Sterman MB, Hoppenbrouwers T 1979 The development of sleep-waking and rest-activity patterns from fetus to adult in man. In: Sterman MB, McGinty DJ. Adinolit A (eds): Brain Development and Behavior. New York, Academic Press, pp 203-227

39. Sullivan ES 1980 Breathing in sleep. In: Orem J, Barnes CD (eds): Breathing in Sleep. New York. Academic Press, pp 213-272

40. Valdes-Dapena MA 1980 Sudden infant death syndrome: a review of the medical literature 1974-1979. Pediatrics 66:597

41. Weissbluth M 1982 Plasma progesterone levels, infant temperature, arousals from sleep, and the sudden infant death syndrome. Med Hypoth 9:215

42. The authors thank Ginette Bouard for her technical assistance and Susan Orsoni for her help with the English version of the manuscript.

43. Requests for reprints should be addressed to Dr. Odile Benoit, Laboratoire de Physiologie, 91 Boulevard de l'Hopital, 75634 Paris Cedex 13, France

44. Received for publication March 1, 1983.

45. Accepted for publication August 18, 1983 . 